\title{
AVALIAÇÃO DO EFEITO DE ÁCIDOS ORGÂNICOS VIA ÁGUA DE BEBIDA DURANTE O MANEJO PRÉ-ABATE SOBRE A MICROBIOTA DO INGLÚVIO, INGESTÃO DE ÁGUA E PERDA DE PESO DE FRANGOS DE CORTE
}

\author{
Jovanir Inês Muller Fernandes ${ }^{1}$ \\ José Carlos Abud Lester Júnior ${ }^{2}$ \\ Bruna Cereda de Oliveira ${ }^{1}$ \\ Edna Tereza de Lima ${ }^{1}$ \\ Karen Prokoski ${ }^{3}$ \\ Anete Rorig ${ }^{3}$
}

FERNANDES, J. I. M.; LESTER JÚNIOR, J. C. A.; OLIVEIRA, B. C. de; LIMA, E. T. de; PROKOSKI, K.; RORIG, A. Avaliação do efeito de ácidos orgânicos via água de bebida durante o manejo pré abate sobre a microbiota do inglúvio, ingestão de água e perda de peso de frangos de corte. Arq. Ciênc. Vet. Zool. UNIPAR, Umuarama, v. 17, n. 1, p. 31-36, jan./mar. 2014.

RESUMO: O objetivo deste trabalho foi avaliar o efeito da adição de ácidos orgânicos comerciais na água de bebida 24 horas antes do abate sobre a perda de peso, a ingestão de água e a microbiota do inglúvio de frangos de corte. Foram utilizados 900 frangos da linhagem Cobb com 45 dias de idade, distribuídos em cinco tratamentos com seis repetições. Os tratamentos consistiram de: A - Controle (sem adição de ácido); B - produto comercial composto por Ácido 2-Hidroxi-4-Metil-Tio-Butanóico (HMTba), ácido propiônico e fórmico, C - produto comercial composto por ácido fórmico, acético e formiato de amônio, D - produto comercial a base de ácido acético (vinagre branco) e E-produto comercial composto por ácido lático e fórmico. Os produtos testados foram diluídos de acordo com a recomendação do fabricante até o pH estabilizar em 4,0. Após a diluição, os produtos foram administrados nos bebedouros por 24 horas antes do abate. Nas últimas oito horas antes do abate, as aves foram pesadas e submetidas ao jejum alimentar. Ao final do período de jejum, as aves foram novamente pesadas, o volume de água ingerido foi registrado e amostras do conteúdo do inglúvio foram coletadas para análises microbiológicas. Não houve diferenças $(\mathrm{p}>0,05)$ na perda de peso em relação à independente da adição de ácidos orgânicos na água de bebida. A ingestão de água pelas aves tratadas com diferentes ácidos orgânicos foi maior $(\mathrm{p}<0,05)$ que de aves não tratadas. A adição de diferentes composições de ácidos orgânicos na água de bebida alterou a ocorrência de E. coli, Proteus spp e Salmonella spp., mostrando que estes aditivos podem ser efetivos, principalmente em condições de desafio sanitário e ambiental em criações comerciais de frangos de corte.

PALAVRAS-CHAVE: Aditivos. Cama de frango. Jejum pré-abate. Salmonella spp.

\section{ASSESSMENT OF THE EFFECT OF ORGANIC ACIDS VIA DRINKING WATER DURING MANAGEMENT IN THE PRE-SLAUGHTER ON THE CROP MICROBIOTA, WATER INTAKE AND WEIGHT LOSS OF BROILER CHICKEN}

\begin{abstract}
The aim of this study is to evaluate the effect of using commercial organic acids in drinking water 24 hours before slaughter on weight loss, water intake and crop microbiota of broiler chicken. A total of 900 Cobb broiler chickens at 45 days of age divided into five treatments with six replicates were used. The treatments consisted of: A - Control (without acid); B - commercial product composed of 2-Hidroxy-4-Methyltio-Butanoic acid (HMTba); acid propionic and formic acid; C - commercial product composed of acid formic, acid acetic and ammonium formate; D - commercial product based on acetic acid (white vinegar); and E - commercial product consisting of lactic and formic acid. The products tested were diluted according to the manufacturer's recommendation until the $\mathrm{pH}$ stabilized at 4.0. After dilution, the products were administered in drinking water for 24 hours before slaughtering. In the last eight hours before slaughter, the birds were weighed and subjected to fasting. At the end of the fasting period, the birds were weighed again, the volume of water ingested was recorded and samples from the crop content were collected for microbiological analyzes. No changes $(p>0.05)$ were observed in weight loss, regardless of the addition of organic acids in the drinking water. The water intake of birds treated with different organic acids was higher $(\mathrm{p}<0.05)$ than the one for untreated birds. The addition of different organic acid compositions in drinking water altered the occurrence of E. coli, Proteus spp and Salmonella sp., showing that these additives can be effective, mainly in challenging sanitary and environmental conditions in commercial broiler flocks.
\end{abstract}

KEYWORDS: Additives. Poultry litter. Pre-slaughter fasting. Salmonella spp.

DOI: https://doi.org/10.25110/arqvet.v17i1.2014.4914

${ }^{1}$ Medica Veterinária, Docente do Programa de Pós-Graduação em Ciência Animal da Universidade Federal do Paraná - UFPR - Setor Palotina. jimfernandes@ufpr.br;

${ }^{2}$ Médico Veterinário, Residente do Departamento de Medicina Veterinária Preventiva da Universidade Estadual de Londrina - UEL. josecjr26@globo.com; ${ }^{3}$ Discente do Programa de Iniciação Científica do Curso de Medicina Veterinária da da Universidade Federal do Paraná - UFPR; 


\section{EVALUACIÓN DEL EFECTO DE ÁCIDOS ORGÁNICOS VÍA AGUA BEBIDA DURANTE EL MANEJO PRE- MATANZA SOBRE LA MICROBIOTA DEL INGLÚVIO, INGESTIÓN DE AGUA Y PÉRDIDA DE PESO EN POLLOS DE ENGORDE}

RESUMEN: El objetivo de este estudio fue evaluar el efecto de la adición de ácidos orgánicos comerciales en el agua potable, 24 horas antes de la matanza, acerca de la pérdida de peso, la ingesta de agua y la microbiota del ingluvio en pollos de engorde. Se ha utilizado 900 pollos Cobb con 45 días de edad, distribuidos en cinco tratamientos con seis repeticiones. Los tratamientos consistieron de: A - Control (sin adición de ácido); B - producto comercial compuesto por Ácido 2-Hidroxi-4-Metil-Tio-Butanoico (HMTBA) ácido propiónico y fórmico, C - producto comercial compuesto por ácido fórmico, acético y formiato de amonio, D - producto comercial a base de ácido acético (vinagre blanco) y E - producto comercial compuesto por ácido láctico y fórmico. Los productos analizados fueron diluidos según las recomendaciones del fabricante hasta que el $\mathrm{pH}$ se estabilizó en 4,0. Después de la dilución, los productos fueron administrados en los bebederos durante 24 horas antes de la matanza. En las últimas ocho horas antes de la matanza, las aves fueron pesadas y sometidas al ayuno alimentar. Al final del período de ayuno, las aves fueron nuevamente pesadas, el volumen de agua ingerido fue grabado y muestras del contenido de ingluvio fueron recogidos para análisis microbiológicos. No hubo diferencias $(\mathrm{P}>0,05)$ en la pérdida de peso en comparación a la independiente de la adición de ácidos orgánicos en el agua de bebida. La ingestión de agua por las aves tratadas con diferentes ácidos orgánicos fue mayor $(\mathrm{p}<0,05)$ que las aves no tratadas. La adición de diferentes composiciones de ácidos orgánicos en el agua potable alteró la incidencia de E. coli, Proteus spp y Salmonella spp., mostrando que esos aditivos pueden ser eficaces, especialmente en condiciones de reto sanitario y ambiental en explotaciones comerciales de pollos de engorde. PALABRAS CLAVE: Aditivos. Cama de pollo. Ayuno pre-matanza. Salmonella spp.

\section{Introdução}

Programas de dieta em animais destinados ao consumo humano têm incluído o fornecimento de antibióticos em doses subterapêuticas e constantes para melhorar o desempenho zootécnico de animais domésticos. No entanto, questionamentos dos mercados consumidores relacionados com a resistência microbiana e o comprometimento da saúde humana culminaram em 2006 com a restrição imposta pela Comunidade Europeia aos mercados produtores que utilizavam de substâncias promotoras (PAPATSIROS et al., 2012).

Visando à substituição dos antibióticos melhoradores no mercado e maior destaque sanitário na produção animal, os ácidos orgânicos foram amplamente distribuídos e aplicados nos diversos sistemas de produção animal, sendo largamente aceito na criação de suínos, com o objetivo de auxiliar na digestão proteica e controlar a proliferação bacteriana intestinal (VIOLA et al., 2008). Em geral, quando o termo ácido orgânico é empregado na produção animal, refere-se aos ácidos fracos, de cadeia curta (C1-C7) (ADIL et al., 2011) que produzem menor quantidade de prótons por molécula ao se dissociarem.

As contaminações e prejuízos durante o processamento das carcaças nas plantas de abates de frangos de corte levaram a inclusão dos ácidos orgânicos em períodos variados que antecedem a restrição alimentar em frangos de corte (SAKI et al., 2012). Na etapa final do manejo pré-abate, quando as aves são submetidas à restrição alimentar, pode ocorrer ingestão de cama de aviário com risco de instalação e proliferação de micro-organismos patogênicos principalmente no inglúvio das aves, pelo $\mathrm{pH}$ favorável, temperatura e grande ingestão de líquido, fatores estes considerados relevantes para a multiplicação bacteriana (BASSAN et al., 2008), sendo os principais reservatórios de micro-organismos patogênicos no trato gastrintestinal de frangos (inglúvio e intestino) (ALZAWQARI et al., 2013).

Estudos demonstram que a adição de ácidos orgânicos na água durante o jejum pré-abate reduz significativamente a quantidade de micro-organismos patógenos na carcaça por meio da descontaminação do inglúvio das aves, principalmente pela alteração do $\mathrm{pH}$. A acidificação do inglúvio tem ação antibacteriana, particularmente contra bactérias gram-negativas (OSTERMANN et al., 2005) e por isso a utilização de ácidos orgânicos deve atender as boas práticas de fabricação e manejo para evitar o desenvolvimento de estirpes resistentes e adaptadas à condição ácida (AÇIKGÖZ; BAYRAKTAR; ALTAN, 2011; MANI-LÓPEZ; GARCÍA; LÓPEZ-MALO, 2012).

Jarquin et al. (2007) verificaram que a adição de uma combinação de ácidos orgânicos na água durante o jejum pré-abate, não só aumentou o consumo de água pelas aves como também diminuiu a perda de peso corporal e, consequentemente, proporcionou carcaças menos desidratadas após o abate. Porém, determinados ácidos podem inibir o consumo de água e aumentar a desidratação das aves durante o jejum alimentar (WOLFENDEN et al., 2007a).

O número e composição dos micro-organismos da microbiota variam consideravelmente ao longo do trato gastrintestinal dos frangos de corte. No inglúvio existe a predominância de lactobacilos que, produzindo ácido lático e acético, reduzem o $\mathrm{pH}$ impedindo o crescimento de bactérias (ALZAWQARI et al,. 2013). O pH no proventrículo e moela é extremamente baixo, próximo de três, e poucas bactérias são capazes de tolerar este ambiente. Já no duodeno, observa-se um $\mathrm{pH}$ neutro em torno de seis a sete, o que viabiliza a colonização por bactérias ácido-resistentes como a Escherichia coli, Salmonella spp e Campylobacter spp do segmento do intestino delgado, bem como o jejuno e íleo. O ceco, com um $\mathrm{pH}$ semelhante, é reconhecido como o segmento de maior colonização de micro-organismos, sendo que grande número de bactérias gram-positivas e negativas estão presentes neste local (ALZAWQARI et al,. 2013).

Segundo Doyle e Erickson (2006), em aves, as bactérias patogênicas como os diferentes sorovares de Salmonella atingem o trato digestório após vencerem a barreira do inglúvio. A existência de um ambiente com $\mathrm{pH}$ baixo neste compartimento é muito importante para impedir ou diminuir a colonização de patógenos no trato digestório. A alta quantidade de Lactobacillus e o pH baixo no inglúvio têm mostrado a redução da ocorrência de Salmonella spp. (HINTON 
JUNIOR et al.,2000).

$\mathrm{O}$ efeito antibacteriano apresenta-se maior na parte anterior do trato digestório, sendo que no trabalho de Thompson e Hinton (1997), houve recuperação dos ácidos fórmico e propiônico principalmente no inglúvio e moela, mostrando maior ação nesses compartimentos. Isso confirma o trabalho de Bolton e Dewar (1964) que demonstra que os ácidos acético, propiônico e butírico usados no nível de 2,5\% na forma de sais de cálcio, são completamente digeridos antes do divertículo de Meckel. Foi visto também que apenas uma pequena porção de acido propiônico da dieta alcança os cecos e final do trato digestório (HUME et al., 1993).

Hayashi (2012) enfatiza que a prática de acidificação via água, comun apenas na fase que antecede o abate, pode não ser efetiva na prevenção da contaminação de carcaças no abatedouro. Esse autor recomenda que a adoção estratégica de uso contínuo durante todo o período de produção pode ser necessária, uma vez que os efeitos da alteração da microbiota, não ocorrem apenas no inglúvio, mas em toda extensão intestinal.

A relação entre o desempenho zootécnico de frangos de corte e o uso de ácidos orgânicos apresenta ainda resultados controversos na literatura, provavelmente devido aos diferentes mecanismos de ação, condições ambientais, dose, produto utilizado e parâmetros avaliados (VIOLA; VIEIRA, 2007; FARIA et al., 2009; ALZAWQARI et al., 2013; AÇIKGÖZ; BAYRAKTAR; ALTAN, 2011).

O objetivo deste trabalho foi avaliar o efeito da adição de ácidos orgânicos comerciais na água de bebida 24 horas antes do abate sobre a perda de peso, a ingestão de água e a microbiota do inglúvio de frangos de corte.

\section{Material e Métodos}

Foram utilizados 900 frangos de corte machos, da linhagem Cobb com 45 dias de idade, distribuídos em cinco tratamentos e seis repetições totalizando 30 unidades experimentais de 30 aves cada. Até os 45 dias de idade, as aves receberam ração comercial e foram manejadas de modo similar. Os tratamentos consistiram de: A - Controle (sem adição de ácido); B - produto comercial composto por Ácido 2-Hidroxi-4-Metil-Tio-Butanoico (HMTba), ácido propiônico e fórmico, $\mathrm{C}$ - produto comercial composto por ácido fórmico, acético e formiato de amônio, D - produto comercial a base de ácido acético (vinagre branco) e E - produto comercial composto por ácido lático e fórmico. Os produtos testados foram diluídosde acordo com a recomendação do fabricante e até o pH estabilizar em 4,0. Após a diluição, os produtos foram administrados nos bebedouros por 24 horas antes do abate. Nas últimas oito horas antes do abate, os comedouros foram retirados e as aves submetidas ao jejum alimentar de acordo com a legislação vigente (MAPA, 2000). As aves foram pesadas no início e fim do período de jejum pré-abate.

Ao final do período pré-abate foram coletadas amostras do conteúdo do inglúvio de uma ave por repetição (seis aves/tratamento). Imediatamente após a coleta, foram realizadas as análises microbiológicas. Os procedimentos das análises e as avaliações foram realizados utilizando-se os parâmetros preconizados pelo MAPA, Instrução Normativa $n^{\circ} 62$, de agosto de 2003 e Portaria $n^{\circ} 126$, de 03 de novembro de 1995 pelo MAPA (1995) modificadas.
O procedimento para isolamento de Salmonella spp. foi realizado de acordo com a metodologia proposta por Mallinson e Snoeyenbos (1989). As amostras foram homogeneizadas e transferidas em $10 \mathrm{~mL}$ de caldo seletivo de enriquecimento (tetrationato e selenito cistina) e incubadas a $37^{\circ} \mathrm{C}$ durante 24 horas. Após a sequência de enriquecimento, alíquotas dos caldos foram transferidas para placas de Petri contendo ágar MacConkey e ágar verde brillhante (AVB), procedendo-se a semeadura em superfície por esgotamento em estrias, com posterior incubação a $37^{\circ} \mathrm{C}$ por 24 horas. Posteriormente, foram selecionadas colônias que apresentavam morfologia típica de Salmonella spp., as quais foram submetidas às provas bioquímicas preliminares em caldo de ureia, agar tríplice açúcar ferro (TSI), Agar Lisina Ferro (LIA) e agar Sulfato Indol Motilidade (SIM) com incubação a $37^{\circ} \mathrm{C}$ por 24 horas.

Para pesquisa de Lactobacillus spp., $1 \mathrm{~mL}$ de cada amostra foi transferido em $5 \mathrm{~mL}$ de caldo Man-Rugosa-Sharpe (MRS), com incubação a $37^{\circ} \mathrm{C}$ por 24 horas em condições de anaerobiose. Após o período de incubação, as culturas foram semeadas em ágar MRS, incubadas a $37^{\circ} \mathrm{C}$ por 24 horas em condições de anaerobiose. A identificação foi baseada nas características morfológicas para o gênero Lactobacillus spp. conforme Davis (1955).

Para análise das bactérias da família Enterobacteriaceae, $1 \mathrm{~mL}$ das amostras foram cultivadas em $5 \mathrm{~mL}$ caldo de Infusão Cérebro-Coração (BHI), com incubação a $37^{\circ} \mathrm{C}$ por 24 horas. Posteriormente, as culturas foram semeadas em ágar sangue, incubadas a $37^{\circ} \mathrm{C}$ por 24 horas. Após o período de incubação, colônias características foram identificadas morfologicamente pela coloração de Gram e submetidas à identificação bioquímica, com base nos testes de fermentação da glicose, lactose, maltose, sacarose, digestão da caseína, Agar tríplice açúcar ferro (TSI), Reação de vermelho de metila (VM), Voges-Proskauer (VP), citrato e prova do Indol.

A análise estatística dos dados foi realizada por intermédio do procedimento GLM do programa SAS (SAS, 2002) com nível de 5\% de significância e em caso de diferença significativa, as médias foram comparadas pelo teste de Tukey (5\%). O teste de Dunnett (análise de contrastes) foi aplicado comparando-se as médias dos tratamentos a base de ácidos com a média das aves controle.

\section{Resultados e Discussão}

Os resultados referentes à perda de peso e à ingestão de água estão demonstrados na Tabela 1. Não foi observada diferença estatística $(\mathrm{p}>0,05)$ para estes parâmetros. Entretanto, na comparação por contrastes (teste de Dunnett), a ingestão média de água entre as aves tratadas com os diferentes ácidos orgânicos foi maior $(\mathrm{p}<0,05)$ que a ingestão de água das aves que não receberam ácidos na água de bebida.

Granjo et al. (2014) adicionaram ácido orgânico comercial composto por ácidos acético, lático, propiônico, tânico e caprílico, na água de bebida dos frangos de corte 12 horas antes do abate e observaram redução do consumo de água pelas aves tratadas em relação as aves controle. Apesar disto, não encontraram diferenças na perda de peso até a apanha, no transporte e no período total. Estes autores concluíram que o uso de ácidos orgânicos na água de bebida inibe o consumo de água, sem proporcionar maior retenção de água na ave. 
Já em trabalhos realizados em granjas comerciais, Urbano (2012) observaram que o uso de ácido orgânico comercial (ácido acético, caprílico, lático, propionico e tanico) diminuiu em média, 25 gramas de peso vivo das aves durante o jejum alimentar ainda na granja e, adicionalmente, reduziu mais 14 gramas durante o transporte, em relação àquelas aves que consumiram apenas água durante jejum alimentar. Em termos percentuais, as aves que consumiram ácidos orgânicos apresentaram perdas de peso totais $35,75 \%$ menores em relação àquelas que não consumiram tais ácidos orgânicos.

Os ácidos orgânicos aumentam a palatabilidade da água e, consequentemente, estimulam a maior ingestão de água pelas aves durante esse período. Devido ao maior nível de hidratação, as aves tendem a perder menos peso, além de reduzir a mortalidade durante o transporte da granja ao abatedouro e as condenações de carcaça no processo de abate (ALZAWQARI et al,. 2013).

Açikgöz, Bayraktar e Altan (2011) utilizaram ácido fórmico na água de bebida das aves durante todo o período de criação e não observaram diferenças no desempenho zootécnico dos frangos de corte.

O resultado do uso, é portanto, dependente da concentração e das combinações dos ácidos empregados bem como da capacidade tamponante da dieta utilizada, daí a importância do uso de blends pois cada classe possui uma determinada função, potencial de dissociação e local de atuação (HAYASHI, 2012). Além disso, outros fatores importantes a serem considerados, são as condições de manejo neste período-pré abate, bem como a época do ano, a densidade de criação (aves $/ \mathrm{m}^{2}$ ) e o nível tecnológico da granja. Estes fatores podem alterar o consumo de água e a perda de peso de forma mais relevante que a adição de aditivos como os ácidos orgânicos.

Paganini (1999) ainda destaca que aves submetidas ao ambiente com temperatura adequada, baixa carga microbiana, baixa densidade e desafio por agentes patogênicos eboa qualidade de ar podem expressar todo seu potencial ge- nético, o que pode contribuir com as diferenças observadas em testes, principalmente, realizados em condições experimentais e comparados com resultados obtidos em granjas comerciais.

Tabela 1: Perda de peso e consumo de água de frangos de corte submetidos ao jejum pré-abate e tratados ou não com ácidos orgânicos na água de bebida.

\begin{tabular}{l|c|c}
\hline & $\begin{array}{c}\text { Perda de } \\
\text { peso }(\mathrm{g})\end{array}$ & $\begin{array}{c}\text { Consumo de } \\
\text { água, } \mathrm{mL} / \mathrm{ave}\end{array}$ \\
\hline Controle & 116,95 & $380,12^{*}$ \\
\hline Tratamentos com ácidos & & \\
\hline $\begin{array}{l}\text { HMTba, ácido propiônico } \\
\text { e fórmico }\end{array}$ & 101,85 & 400,73 \\
\hline $\begin{array}{l}\text { Ácido fórmico, acético e } \\
\text { formiato de amônio }\end{array}$ & 144,83 & 420,05 \\
\hline Ácido acético & 141,67 & 421,33 \\
\hline Ácido lático e fórmico & 103,82 & 410,85 \\
\hline Média & 123,04 & $413,24 *$ \\
\hline CV, \% & 16,36 & 13,08 \\
\hline $\begin{array}{l}\text { Valor de p } \\
*\end{array}$ & $\mathrm{~ns}$ & $\mathrm{~ns}$
\end{tabular}

* Teste de Dunnet $(\mathrm{p}<0,05)$

Na Tabela 2 observa-se que a contagem de coliformes foi bastante variável em relação aos ácidos orgânicos utilizados. A ingestão da água de bebida com a adição dos produtos comerciais compostos por HMTba e ácido propiônico e fórmico e por ácido lático e fórmico não preveniram o crescimento dessas bactérias. A contagem de E. coli e de Hafnia alvei foi intermediária para o tratamento composto por ácido acético (vinagre) e para o controle e menor para os tratamentos a base de ácido fórmico, acético e formiato de amônico. Já para Proteus spp e Lactobacillus spp houve crescimento em $100 \%$ das amostras avaliadas, independente dos tratamentos.

Tabela 2: Isolado de bactérias (Escherichia coli, Proteusspp, Lactobacillusspp e Hafnia alvei) do inglúvio de frangos de corte submetidos ao jejum pré-abate e tratados ou não com ácidos orgânicos na água de bebida.

\begin{tabular}{|c|c|c|c|c|c|c|c|c|}
\hline & \multicolumn{2}{|c|}{ E. coli } & \multicolumn{2}{|c|}{ Proteus spp. } & \multicolumn{2}{|c|}{ Lactobacillus spp } & \multicolumn{2}{|c|}{ Hafnia alvei } \\
\hline & $\mathrm{n}^{*}$ & $\% * *$ & $\mathrm{n}$ & $\%$ & $\mathrm{n}$ & $\%$ & $\mathrm{n}$ & $\%$ \\
\hline Controle & 5 & 83,3 & 6 & 100,0 & 6 & 100,0 & 3 & 50,0 \\
\hline HMTba, ácido propiônico e fórmico & 6 & 100,0 & 6 & 100,0 & 6 & 100,0 & 4 & 66,7 \\
\hline Ácido fórmico, acético e formiato de amônio & 3 & 50,0 & 6 & 100,0 & 6 & 100,0 & 1 & 16,7 \\
\hline Ácido acético & 5 & 83,3 & 6 & 100,0 & 6 & 100,0 & 3 & 50,0 \\
\hline Ácido lático e fórmico & 6 & 100,0 & 6 & 100,0 & 6 & 100,0 & 3 & 50,0 \\
\hline
\end{tabular}

*n: número de aves positivas, **percentual de aves positivas em relação ao número de aves amostradas

Para o isolamento de Salmonella spp em meio Tetrationato (Tabela 3), observou-se que o produto comercial a base de ácido fórmico, acético e amônico e ácido lático e fórmico permitiram o crescimento em $16,7 \%$ das amostras, já para os demais tratamentos não houve crescimento. Para o meio Selenito/Cistina houve crescimento de Salmonella spp em $50 \%$ das amostras quando o ácido acético foi adicionado e em $16,7 \%$ das amostras quando o produto comercial composto por ácido lático e fórmico foi adicionado. Este resultado sugere que os ácidos orgânicos podem reduzir a contagem de coliformes e aumentar bactérias láticas na microbiota intestinal e pelo mecanismo de exclusão competitiva poderia diminuir a viabilidade da Salmonella spp.

O período de privação alimentar horas antes o abate favorece o aumento do $\mathrm{pH}$ intestinal devido ao decréscimo do número de Lactobacillus e, consequentemente, de ácido lático, proporcionando um ambiente favorável para a instalação e desenvolvimento de bactérias patogênicas (SAKI et al., 2012). Estas condições associadas com a ingestão de outros materiais disponíveis, como fezes e resíduos da cama, au- 
mentam o potencial de contaminação das carcaças no abatedouro (CASTRO et al., 2008; MENDES, 2001).

Tabela 3: Isolamento de Salmonella spp em meios de enriquecimento seletivos do inglúvio de frangos de corte submetidos ao jejum pré-abate e tratados ou não com ácidos orgânicos na água de bebida.

\begin{tabular}{l|c|c|c|c}
\hline & \multicolumn{2}{|c|}{$\begin{array}{c}\text { Salmonellaspp. } \\
\text { Meio Tetratio- } \\
\text { nato }\end{array}$} & \multicolumn{2}{c}{$\begin{array}{c}\text { Salmonellaspp. } \\
\text { Meio Selenito/ } \\
\text { Cistina }\end{array}$} \\
\hline & $\mathrm{n}$ & $\%$ & $\mathrm{n}$ & $\%$ \\
\hline Controle & 0 & 0,0 & 0 & 0,0 \\
\hline $\begin{array}{l}\text { HMTba, ácido propiô- } \\
\text { nico e fórmico }\end{array}$ & 0 & 0,0 & 0 & 0,0 \\
\hline $\begin{array}{l}\text { Ácido fórmico, acético } \\
\text { e formiato de amônio }\end{array}$ & 1 & 16,7 & 0 & 0,0 \\
\hline Ácido acético & 0 & 0,0 & 3 & 50,0 \\
\hline Ácido lático e fórmico & 1 & 16,7 & 1 & 16,7 \\
\hline
\end{tabular}

Rezende et al. (2008) avaliaram diferentes níveis de inclusão de ácido acético $(0 ; 0,5 \% ; 1,0 \%, 1,5 \%$ e $2,0 \%)$ em rações de frango experimentalmente contaminadas com Salmonella e observaram que a inclusão do ácido em todos os níveis avaliados melhorou os parâmetros zootécnicos dos animais (ganho de peso e conversão alimentar), porém, no que se refere ao controle microbiológico, o uso do produto não foi satisfatório.

Um aspecto importante a ser destacado é que em situações de lotes positivos para Salmonella spp., a utilização de vinagre pode não ser efetiva para evitar a proliferação destes agentes no trato gastrointestinal das aves. Estudos realizados com a inclusão do ácido acético em rações contaminadas com Salmonella spp. também não se mostraram efetivos no que se refere ao controle microbiológico, no entanto, sua inclusão melhorou os parâmetros zootécnicos das aves (REZENDE et al., 2008).

Por outro lado, em experimentos anteriormente realizados, foi obtida a redução significativa da concentração de Salmonella Enteritidis em tonsilas cecais e trato gastrointestinal quando foi adicionado ácidos orgânicos na água de bebida (WOLFENDEN et al., 2007b; JARQUIN et al., 2007).

Em aves, as bactérias patogênicas (e.g. Salmonela) atingem o trato digestório após vencerem a barreira do inglúvio, onde a existência de um ambiente ácido é muito importante para impedir ou diminuir a colonização de patógenos no trato digestório. A alta quantidade de Lactobacilus spp e $\mathrm{pH}$ baixo no inglúvio têm mostrado reduzir a ocorrência de Salmonella spp.(HINTON JUNIOR et al., 2000), apesar disso não ser observado neste trabalho.

Em relação ao desempenho produtivo, estudos realizados com ácidos lático, fórmico e acético na dieta e o fornecimento destes ácidos com ácido fosfórico na água de bebida melhoram o ganho de peso de frangos de corte em comparação ao uso de dietas isentas de antibióticos promotores de crescimento (VIOLA et al., 2008).

Resultados contraditórios têm sido relatados sobre a suplementação com ácidos orgânicos em dietas para frangos de corte, possivelmente em razão das diferenças no mecanismo de ação, condição ambiental, dose utilizada, período de jejum e resposta avaliada (SAKI et al., 2012). No entanto, um número crescente de trabalhos com o uso de acidificantes vem surgindo, o que permite comparações sobre o uso destes produtos.

\section{Conclusão}

A adição de ácidos orgânicos comerciais na água de bebida 24 horas antes do abate não reduziu a perda de peso dos frangos de corte no período em que houve a restrição alimentar. O consumo médio de água pelas aves tratadas com diferentes ácidos orgânicos foi maior em comparação com as aves não tratadas.

Houve efeito variável sobre o isolamento de bactérias no inglúvio dos frangos de corte tratados com ácidos orgânicos, mostrando haver diferenças entre os ácidos, o que implica na necessidade de mais experimentos e que estes sejam realizados em granjas comerciais, principalmente em condições de desafio sanitário, de manejo e ambiental e portanto, podem comprovar o efeito benéfico destes produtos.

\section{Referências}

AÇIKGÖZ, Z.; BAYRAKTAR, H.; ALTAN, Ö. Effects of formic acid administration in the drinking water on performance, intestinal microflora and carcass contamination in male broilers under high ambient temperature. Asian-Australian Journal Animal Science, Seoul, v. 24, n.1, p. 96-102, 2011.

ADIL, S. et al. Response of broiler chicken to dietary supplementation of organic acids. Journal of Central European Agriculture, Nitra, v. 12, n. 3, p. 498-508, 2011.

ALZAWQARI, M. H. et al. Impact of feed withdrawal and addition of acetic acid in drinking water during preslaughter phase on intestinal microbiota of broilers. African Journal of Biotechnology, Benin City, v. 12, n.10, p.1164-1167, 2013.

BASSAN, J. D. et al. Controle da Infecção por Salmonella enteritidis em frangos de cortes com ácidos orgânicos e mananoligossacarídeos. Ciência Rural, Santa Maria, v. 38, n. 7, p. 1961-1965, 2008.

BOLTON, W.; DEWAR, W. A. The digestibility of acetic, propionic and butyric acids by the fowl. British Poultry Science, London, v. 6, n. 1, p. 103-105, 1964.

CASTRO, J. B. J. et al. Jejum alimentar na qualidade da carne de frangos de corte criados em sistemas convencional. Ciência Rural, Santa Maria, v. 38, n. 2, p. 470-476, 2008.

DAVIS, G. H. G. The classification of Lactobacilli from the human mouth. Journal of General Microbiology, Oxford, v.13, n. 4, p. 481-493, 1955.

DOYLE, M. P.; ERICKSON, M. C. Reducing the carriage of foodborne pathogens in livestock and poultry. Poultry Science, Champaign, v. 85, n. 8, p. 960-973, 2006. 
FARIA, D. E. et al. Alternativas ao uso de antibióticos promotores de crescimento para frangos de corte: 2 . ácidos orgânicos e probióticos. Ciência Animal Brasileira, Goiânia, v. 10, n. 1, p. 29-39, 2009.

GRANJO, V. P. et al. Consumo de ácidos orgânicos via agua de bebida durante o manejo pré-abate e seus efeitos sobre a ingestão de agua e perda de peso de frangos de corte. In: CONGRESSO BRASILEIRO DE ZOOTECNIA, 24., 2014, Vitória. Anais... Espírito Santo: Zootec, CD-ROM.

HAYASHI, R. Acidificantes ganham espaço na alimentação animal. A Lavoura, Rio de Janeiro, n. 689, p. 20-23, 2012.

HINTON JUNIOR, A. et al. Reduction of Salmonella in the crop ofbroiler chickens subjected to feed withdrawal. Poultry Science, Champaign, v.79, n.11, p.1566-1570, 2000.

HUME, M. E. et al. Metabolism of propionic acid in broiler chicks. Poultry Science, Champaign, v. 72, n. 4, p. 786793, 1993.

JARQUIN, R. L. et al. The evaluation of organic acids and probiotic cultures to reduce Salmonella enteritidis horizontal transmission and crop infection in broiler chickens. International Journal of Poultry Science, Champaign, v. 6, n. 1, p. 182-186, 2007.

MALLINSON, E. T.; SNOEYENBOS, G. H. Salmonellosis. In: PURCHASE, H. G. et al. (Ed.). A laboratory manual for the isolation and identification of avian pathogens. 3. ed. Pennsylvania: American Association of Avian Pathologists, University of Pennsylvania, 1989. p. 3-11.

MANI-LÓPEZ, E.; GARCÍA, H. S.; LÓPEZ-MALO, A. Organic acids as antimicrobials to control Salmonella in meat and poultry products. Food research international, Ottawa, v. 45, n. 2, p. 713-721, 2012.

MAPA - MINISTÉRIO DA AGRICULTURA, PECUÁRIA E DO ABASTECIMENTO. Secretaria de Defesa Agropecuária. Portaria Ministerial n 193, 19 de setembro de 1995. Institui o Programa Nacional de Sanidade Avícola e cria o Comitê Consultivo do PNSA. Disponível em: <http://extranet.agricultura. gov.br/sislegisconsulta/consultarLegislacao.do? operacao $=$ visualizar\&id $=2635>$. Acesso em: 13 maio, 2014.

Instrução normativa no $\mathbf{3}$, de 17 de janeiro de 2000. In: FORUM NACIONAL DO MINISTÉRIO DA AGRICULTURA E ABASTECIMENTO. Disponível em: $<$ http://www.forumnacional.com.br/instr_normativa_n_03 de_17_01_2000.pdf >. Acesso em: 13 maio 2014.

MENDES, A. A. Jejum pré-abate em frangos de corte.

Revista Brasileira Ciência Avicola, Campinas, v. 3, n. 3, p. 199-209, 2001.

OSTERMANN, P. et al. Metabolismo e bases conceituais para a ação benéfica de ácidos orgânicos para frangos de corte. Ave World: A Revista do Agricultor Moderno, a. 3, n. 15, p. $28-31,2005$.

PAGANINI, F. J. Aspectos microbiológicos na reutilização da cama de frangos de corte. Avicultura industrial, Campinas, v.1074, p.76-77, 1999.

PAPATSIROS, V. G. et al. The use of organic acids in monogastric animals (swine and rabbits). Journal Cell Animal Biology, Bein City, v. 6, n. 1, p. 154-159, 2012.

REZENDE, C. S. M. et al. Ácido acético em rações de frangos de corte experimentalmente contaminadas com Salmonella Enteritidis e Salmonella Typhimurium. Revista Brasileira de Saúde e Produção Animal, Salvador, v. 9, n. 3 , p. 516-528, 2008

SAKI, A. A. et al. Herbal additives and organic acids as antibiotic alternatives in broiler chickens diet for organic production. African Journal of Biotechnology, Benin City, v.11, n. 8, p. 2139-2145, 2012.

\section{SAS - STATISTICAL ANALYSIS SYSTEM. User's}

Guide, Version 9, 4. ed. North Caroline: SAS Institute INC. 2002.

THOMPSON, J. L.; HINTON, M. Antibacterial activity of formic and propionic acids in the diet of hens on salmonellas in the crop. British Poultry Science, London, v. 38 , n. 1, p. 59-65, 1997.

URBANO, T. Manejo pré-abate, como minimizar os efeitos negativos desse manejo. 2012. Disponível em: $<$ http://www.aveworld.com.br/noticia $>$. Acesso em: $12 \mathrm{dez}$. 2013.

VIOLA, E. S.; VIEIRA, S. L. Suplementação de acidificantes orgânicos e inorgânicos em dietas para frangos de corte: desempenho zootécnico e morfologia intestinal. Revista Brasileira de Zootecnia, Viçosa, v. 36, n. 4, p. 1097-1104, 2007.

VIOLA, E. S. et al. Desempenho de frangos de corte sob suplementação com ácidos lático, fórmico, acético e fosfórico no alimento ou na água. Revista Brasileira de Zootecnia, Viçosa, v. 37, n. 2, p. 296-302, 2008.

WOLFENDEN, A. D. et al. Effect of an organic acid product during feed withdrawal on broiler mortality, shrinkage and carcass condemnation following transport to processing. International Journal of Poultry Science, Wallingford, v. 6, n. 7, p. 497-500, 2007a.

WOLFENDEN, A. D. et al. Effect of organic acids and probiotics on Salmonella enteriditis infection in broiler chickens. International Journal of Poultry Science, Wallingford. v. 6, n. 3, p. 403-405, 2007b. 